\title{
MENGEMBANGKAN KREATIVITAS ANAK USIA DINI MELALUI MENGGAMBAR DENGAN TEKNIK INKBLOT
}

AIP SARIPUDIN*

IAIN Syekh Nurjati Cirebon

ERY KHAERIYAH

IAIN Syekh Nurjati Cirebon

ROSMITA AYU LESTARI

IAIN Syekh Nurjati Cirebon asaripudin@syekhnurjati.ac.id

erykhaeriyah21@syekhnurjati.ac.id

rosmitaayu21@gmail.com

- Received: 2 April 2020 •Accepted: 26 Mei 2020 •Published online: 30 Juni 2020

\section{Abstract:}

Penelitian ini dilatar belakangi oleh kreativitas anak usia dini pada kelompok B masih rendah. Terbukti dari indikator kreatifitas yakni mampu menyesuaikan warna, menggambar bentuk, keluwesan dalam menggambar objek yang ditiru masih terbatas. Hal ini tidak terlepas dari stimulasi di lembaga PAUD yang masih terbatas. Kegiatan menggambar belum sepenuhnya diterapkan secara maksimal oleh guru. Penggunaan Lembar Kerja Anak (LKA) juga menjadi salah satu factor anak belum mampu mengekspresikan ide dan gagasannya dalam bentuk gambar-gambar sederhana. Adapun tujuan penelitian ini adalah mengetahui penerapan teknik inkblot untuk meningkatkan kreativitas anak melalui kegiatan menggambar. Jenis penelitian yang digunakan adalah Penelitian Tindakan Kelas dengan model Kemmis dan Mc Taggart. Subjek dalam penelitian ini sebanyak 20 anak. Data dikumpulkan melalaui observasi, dokumentasi dan wawancara. Hasil penelitian menunjukan bahwa terdapat peningkatan yang signifikan dalam kreatifitas anak usia dini. Peningkatan tersebut terlihat dari penggunaan media menggambar dengan bantuan stimulasi teknik Inkblot yang dilakukan oleh peneliti. Hal ini terlihat dari indikator capaian perkembangan anak melalui dua siklus memperoleh nilai sebesar 88,45\%. Artinya nilai tersebut berada pada level sangat baik atau berkembang sangat baik, sehingga untuk mengembangkan anak dalam aspek kreatifitas salah satunya dapat dilakukan melalaui menggambar langsung dengan teknik inkblot.

Kata kunci: PAUD; menggambar; teknik inkblot.

\begin{abstract}
This research is motivated by the low creativity of early childhood in group B. Evidenced by the indicators of creativity, namely being able to adjust colors, draw shapes, flexibility in drawing objects that are imitated is still limited. This is inseparable from the limited stimulation in PAUD institutions. Drawing activities
\end{abstract}

${ }^{*}$ Corresponding Aip Saripudin, Email:asaripudin@syehknurjati.ac.id 
have not been fully implemented by the teacher. The use of children's worksheets (LKA) is also one of the factors that children are unable to express their ideas and ideas in the form of simple pictures. The purpose of this study was to determine the application of the inkblot technique to improve children's creativity through drawing activities. The type of research used is Classroom Action Research with the model of Kemmis and Mc Taggart. The subjects in this study were 20 children. Data were collected through observation, documentation and interviews. The results showed that there was a significant increase in the creativity of early childhood. This increase can be seen from the use of drawing media with the help of stimulation of the Inkblot technique carried out by the researcher. This can be seen from the indicators of the achievement of children's development through two cycles obtaining a value of $88.45 \%$. This means that the value is at a very good level or very well developed, so that to develop children in the aspect of creativity, one of them can be done by drawing directly with the inkblot technique.

Keywords: ECE; drawing;inkblot tecknique.

\section{A. PENDAHULUAN}

Anak usia dini merupakan usia dimana tumbuh kembang anak sedang berkembang sangat pesat. Menurut NAEYC anak berada pada rentang usia 0-8 tahun. Pada masa ini proses pertumbuhan dan perkembangan dalam berbagai aspek sedang mengalami masa yang cepat dalam rentang perkembangan hidup manusia (Sujiono \& Nuraini, 2009). Dalam undang-undang tentang sistem pendidikan nasional, dinyatakan bahwa pendidikan anak usia dini adalah suatu upaya pembinaan yang ditujukan kepada anak sejak lahir sampai dengan usia enam tahun yang dilakukan melalui pemberian rangsangan pendidikan untuk membantu pertumbuhan jasmani dan rohani agar anak memiliki kesiapan dalam memasuki pendidikan lebih lanjut.

Pendidikan Anak Usia Dini pada hakikatnya ialah pendidikan yang selenggarakan dengan tujuan untuk memfasilitasi pertumbuhan dan perkembangaan anak secara menyeluruh atau menekankan pada pengembangan seluruh aspek kepribadian anak (Suyadi \& Maulidya Ulfah, 2015). Oleh karena itu PAUD memberi kesempatan kepada anak untuk mengembangkan kepribadian dan potensi secara maksimal. Salah satu periode yang menjadi ciri masa usia dini adalah the golden age atau masa keemasan. Mengacu pada teori Piaget, anak usia dini dapat dikatakan sebagai usia yang belum dapat dituntut untuk berpikir secara logis, yang ditandai dengan pemikiran sebagai berikut (Wilyani \& Barnawi, 2011): Berpikir secara konkret, Realisme, Egosentris, Kecenderungan untuk berpikir sederhana dan tidak mudah menerima sesuatu yang majemuk, Animisme, dan Sentrasi.

Menurut UNESCO ECCE (Early Childhood Care and Education) tujuan Pendidikan Anak Usia Dini antara lain sebagai berikut: pertama untuk Membagun fondasi awal 
Aip Saripudin, Ery Khaeriyah, Rosmita Ayu Lestari

dalam meningkatkan kemampuan anak untuk menyelesaikan pendidikan lebih tinggi, menurunkan angka mengulang kelas dan angka putus sekolah. Kedua untuk menanamkan investasi SDM yang menguntungkan, baik keluarga, bangsa, negara, maupun agama. Ketiga untuk menghentikan roda kemiskinan, dan turut serta aktif menjaga dan melindungi hak atasi setiap anak untuk memperoleh pendidikan yang dijamin oleh undang-undang.

Kreativitas merupakan pengalaman mengekspresikan dan mengaktualisasikan identitas individu dalam bentuk terpadu dalam hubungan dengan diri sendiri, dengan alam orang lain (Munandar,2009). Kreativitas adalah kemampuan menghasilkan bentuk baru dalam seni, atau memecahkan masalah-masalah dengan menggunakan metode baru (Rachmawati \& Kurniati, 2011). Kegiatan pengembangan kreatifitas anak usia dini pada Kelompok B TK Handayani belum menunjukan kegiatan peengembangan yang signifikan. Stimulasi yang dilakukan oleh guru masih pada tahap pengenalan melalui lembar kerja anak. Dalam satu minggu anak hanya memperoleh stimulasi pengembangan kreativitas hanya satu kali dalam seminggu. Kecenderungan guru memberikan perintah berupa tugas-tugas yang harus dikerjakan siswa melalui LKA yang ada di sekolah. Guru belum memberikan kebebasan anak untuk mengeksplor kemampuan berpikir dan berimajinasi yang dapat dituangkan dalam bentuk gambar. Hasil observasi awal menunjukan capaian indikator kreatifitas anak usia dini berbeda satu dengan yang lainnya. Ada anak yang mengambar sangat rapih, mengikuti pola gambarnya dan mementingkan estetika keindahan di dalamnya. Guna meningkatan kemampuam kreativitasnya anak perlu diberi ruang dan kebebasan untuk melakukan segala sesuatunya misalnya dengan kegiatan menggambar dengan teknik yang berbeda, yakni dengan teknik Inkblot. Teknik Inkblot adalah cara membuat kreasi gambar bebas yang dilakukan dengan meneteskan atau menggoreskan cairan warna diatas sebagian bidang gambar setelah itu bidang gambar yang tidak ditetesi warna dilipatkan kemudian ditekan-tekan, setelah itu buka kertas hvsnya secara perlahan-lahan. Bahan dan alat yang diperlukan, yaitu Adonan yang sudah diberi warna. Terbuat dari Lem, pewarna makanan, dan bedak bayi, Buku gambar atau selembar kertas, Koran bekas dan Tusuk sate.

Kreativitas merupakan suatu proses mental individu yang melahirkan gagasan, proses, metode, ataupun produk baru yang efektif yang diferensiasi yang berdaya guna dalam berbagai bidang pemecahan suatu masalah. Adapun proses kreatif hanya akan terjadi jika dibangkitkan melalui masalah yang memacu pada lima macam perilaku 
kreatif, sebagaimana yang dipaparkan oleh Parnes sebagai berikut (Rachmawati \& Kurniati, 2011): Fluency (kelancaran), yaitu kemampuan mengemukakan ide yang serupa untuk memecahkan suatu masalah, Flexibility (keluwesan), yaitu kemampuan untuk menghasilkan berbagai macam ide guna memecahkan suatu masalah diluar kategori yang biasa, Originality (keaslian), yaitu kemampuan memberikan respons yang unik atau luar biasa, dan Elaboration (keterperincian), yaitu kemampuan menyatakan pengarahan ide secara terperinci untuk mewujudkan ide menjadi kenyataan, dan Sensitivity (kepekaan), yaitu kepekaan menangkap dan menghasilkan masalah sebagai tanggapan terhadap suatu situasi.

Menggambar bagi anak adalah media berekspresi dan berkomunikasi yang dapat menciptakan suasana aktif, asyik dan menyenangkan (Sadiah Kusumahwati, 2012). Aktivitas menggambar dalam penelitian adalah proses ketika anak membuat gambar dengan cara menggoreskan pensil atau spidol pada selembar kertas, yang merupakan suatu pernyataan yang berupa tiruan objek ataupun fatasi yang lengkap dengan garis, bidang, warna, dan tekstur dengan sederhana. Tujuan menggambar dalam penelitian ini adalah sebagai media mencurahkan perasaan ide-ide atau gagasan yang dimiliki anak, sebagai alat atau media untuk bermain, dan sebagai alat untuk melatih serta mengembangkan kreativitas anak khususnya kreativitas menggambar. Manfaat menggambar dalam penelitian ini anak akan mengalami kegembiraan, anak terampil dalam menggambar, dan kreativitas menggambar anak berkembang dengan baik.

\section{B. METODOLOGI PENELITIAN}

Penelitian ini menggunakan jenis Penelitian Tindakan Kelas (PTK). Penelitian tindakan kelas merupakan suatu kegiatan penelitian dengan mencermati sebuah kegiatan be;ajar yang diberikan tindakan, yang secara sengaja dimunculkan dikelas, yang bertujuan memecahkan masalah atau meningkatkan mutu pembelajaran dikelas (Nizar Alam Hamdani dan Dody Hermana, 2008). Penelitian ini dilakukan secara kolaboratif melalui kerjasama dengan pihak lain, dan peneliti sekaligus sebagai praktisi yang melakukan refleksi. Penelitian tindakan kelas kolaboratif yang mana peneliti terlibat langsung dalam proses penelitian sejak awal sampai dengan hasil penelitian yang berupa laporan. Mulai dari perencanaan penelitian, kemudian peneliti memantau, mencatat, melakukan pengumpulan data, menganalisis data, serta melaporkan hasil penelitian (Nizar Alam Hamdani dan Dody Hermana, 2008). Adapun indikator keberhasilan tindakan mengikuti ketentuan sebagai berikut: 
Aip Saripudin, Ery Khaeriyah, Rosmita Ayu Lestari

1. BSB (Berkembang Sangat Baik), apabila nilai yang diperoleh anak 85\%-100\%.

2. BSH (Berkembang Sesuai Harapan), apabila nilai yang diperoleh anak 75\%-84\%.

3. MB (Mulai Berkembang), apabila nilai yang diperoleh anak 51\%-74\%.

4. BB (Belum Berkembang), apabila nilai yang diperoleh anak 21\%-50\%. (Suharsimi, 2012)

\section{RESULT AND DISCUSSION}

Kreativitas merupakan pengalaman mengekspresikan dan mengaktualisasikan identitas individu dalam bentuk terpadu dalam hubungan dengan diri sendiri, dengan alam orang lain (Munandar,2009). Penellitian ini terdiri dari tiga tahapan yakni tahap pra siklus yang dilakukan untuk memperoleh data-data pendahuluan tentang kreatifitas anak usia dini. Pra siklus dilakukan selama 3 hari. Kemudian dilanjutkan dengan siklus 1 yakni melakukan kegiatan pembelajaran sesuai dengan tema-tema yang ada di sekolah, namun pada kegiatan tersebut disisipkan kegiatan kreatifitas seuai dengan tema yang ada. Pada siklus satu ini dilakukan selama 6 kali pertemuan dalam kurun waktu kurang lebih 2 minggu. Pada siklus 2 juga dilakukan dalam 6 kali pertemuan dan siklus 2 dilakukan selama 6 kali pertemuan dalam kurun waktu kurang lebih 2 minggu. Langkahlangkah yang dilakukan pada setiap siklus yaitu perencanaan, pelaksanaan, observasi dan refleksi. Tindakan dilakukan pada setiap siklus yakni kegiatan menggambar dengan menggunakan teknik inkblot. Adapun setiap kali pertemuan, tema atau materi yang diberikan kepada anak-anak berbeda beda, hal ini sesuai dengan tema yang sedang berlangsung disekolah, sehingga peneliti hanya memasukan unsur-unsur menggambar dengan inkblot ke dalam materi tersebut.

Menurut Piaget berpendapat bahwa apa yang dilakukan anak melalui gambar coret mencoret adalah kreativitas spontan (Rusdarmawan, 2009). Menggambar adalah membuat gambar yang dilakukan dengan cara mencoret, menggores, menorehkan benda tajam ke benda lainnya dan memberi warna sehingga menimbulkan warna (Pamadhi dan Sukadi, 2008). Pelaksanaan pra siklus adalah masa pengamatan, pada siklus 1 yaitu melaksanakan perencanaan yang telah direncanakan bersama guru kelas B, sedangkan pada siklus 2 yaitu langkah yang diambil untuk memperbaiki hasil yang diperoleh saat siklus 1 sehingga dapat mencapai nilai indikator keberhasilan sebesar 75$84 \%$.

Setiap permasalahan yang muncul perlu adanya perbaikan sehingga dapat mencapai target yang diharapkan. Pengamatan dilakukan dengan menggunakan lembar 
Abdul Aziz, Akhmad Shodikin, Mohammad Rana

observasi yang telah divalidasi oleh ahli pakar, selanjutnya hasilnya untuk mengetahui peningkatan kreativitas anak melalui menggambar dengan teknik inkblot pada setiap pertemuan.

Hasil observasi yang dilakukan dikelompok B TK Handayani pada pra siklus, siklus 1 dan siklus 2. Perkembangan Kreativitas setiap anak selalu menggalami kenaikan pada setiap pertemuannya, dapat dilihat dari tabel rekapitulasi hasil observasi dibawah ini:

Tabel 1

Rekapitulasi Hasil Observasi Pra Siklus, Siklus 1 dan Siklus 2

\begin{tabular}{|c|c|c|c|c|c|}
\hline \multirow[t]{2}{*}{ No } & \multirow[t]{2}{*}{ Nama Anak } & \multicolumn{3}{|c|}{ Prosentase } & \multirow[t]{2}{*}{ Kenaikan } \\
\hline & & $\begin{array}{l}\text { Pra } \\
\text { Siklus }\end{array}$ & Siklus 1 & Siklus 2 & \\
\hline 1 & NSF & 45 & 75 & 91 & 46 \\
\hline 2 & AS & 44 & 62 & 90 & 46 \\
\hline 3 & $\mathbf{A P}$ & 53 & 77 & 93 & 40 \\
\hline 4 & $\mathbf{Z}$ & 41 & 50 & 81 & 40 \\
\hline 5 & DA & 46 & 76 & 90 & 44 \\
\hline 6 & PAS & 44 & 61 & 90 & 46 \\
\hline 7 & MKA & 42 & 53 & 84 & 42 \\
\hline 8 & AMA & 55 & 78 & 94 & 39 \\
\hline 9 & AW & 56 & 78 & 93 & 37 \\
\hline 10 & MP & 43 & 57 & 84 & 41 \\
\hline 11 & WS & 44 & 63 & 94 & 50 \\
\hline 12 & SS & 43 & 58 & 84 & 41 \\
\hline 13 & $\mathbf{J P}$ & 41 & 53 & 84 & 43 \\
\hline 14 & AAK & 51 & 76 & 92 & 41 \\
\hline 15 & $\mathbf{A M}$ & 51 & 78 & 94 & 43 \\
\hline 16 & IYA & 45 & 53 & 84 & 39 \\
\hline 17 & JRW & 42 & 55 & 84 & 42 \\
\hline 18 & FNZS & 44 & 63 & 90 & 46 \\
\hline 19 & NCY & 46 & 61 & 89 & 43 \\
\hline 20 & MS & 42 & 50 & 84 & 42 \\
\hline \multicolumn{2}{|c|}{ Junlah } & 918 & 1277 & 1769 & \\
\hline \multicolumn{2}{|c|}{ Rata-rata } & 45,9 & 63,85 & 88,45 & \\
\hline
\end{tabular}

Berdasarkan data diatas dapat diketahui bahwa setiap anak memiliki kemampuan kreativitas anak yang berbeda-beda, ada anak yang mencapai nilai BSB ( Berkembang Sangat Baik) dan ada juga anak yang mencapai nilai BSH (Berkembang Sesuai Harapan). Hal ini terbukti dari sebelum melakukan tindakan (pra siklus) sampai 
Aip Saripudin, Ery Khaeriyah, Rosmita Ayu Lestari

dengan siklus 2 telah menunjukan peningkatan yang signifikan. Hal ini dilatar belakangi dengan penerapan teknik inkblot dalam meningkatkan kreativitas anak.

Guna melihat hasil prosentase peningkatan kreativitas anak melalui menggambar dengan teknik inkblot dari pra siklus, siklus 1 dan siklus 2 dapat dilihat pada grafik dibawah ini:

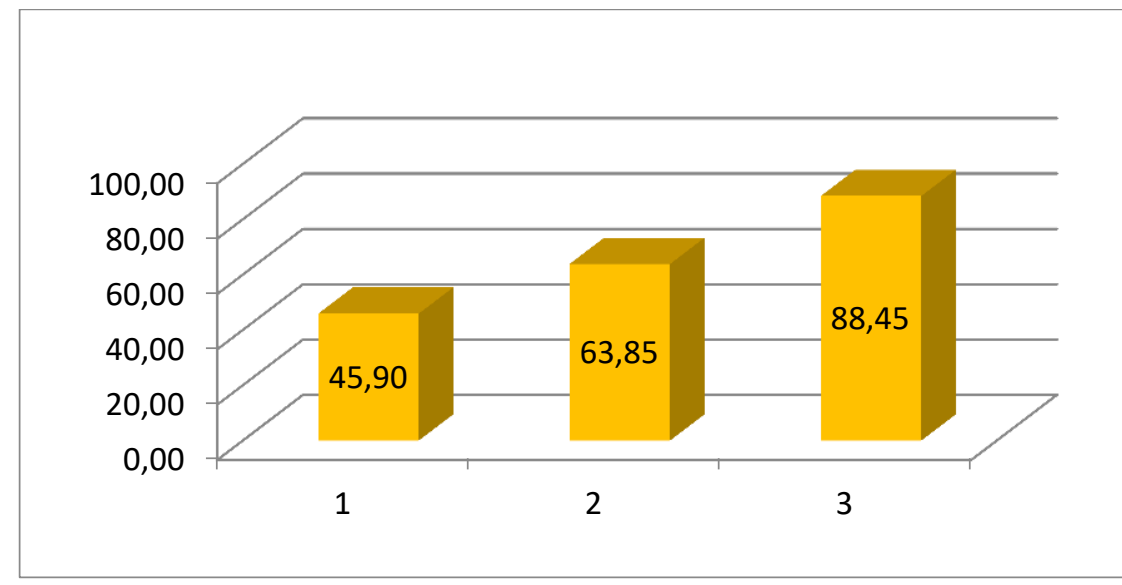

\section{Grafik 1}

\section{Prosentase setiap pertemuan}

Grafik diatas dapat dijadikan acuan bahwa kemampuan kreativitas anak melalui menggambar dengan teknik inkblot anak memperoleh niali rata-rata pada setiap siklusnya, yaitu pada Pra siklus memperoleh nilai sebesar 45,90\% artinya kemapuan kreativitas anak masuk kriteria BB (Belum Berkembang), selanjutnya pada siklus 1 memperoleh nilai sebesar 63,85\% artinya kemampuan kreativitas anak masuk dalam kriteria MB (Mulai Berkembang) dan meningkat sebesar 18\%, sedangkan pada siklus 2 memperoleh nilai sebesar 88,45\% artinya kemampuan kreativitas anak masuk dalam kriteria BSB (Berkembang Sangat Baik) dan meningkat sebesar 24\%.

Menggambar adalah membuat gambar yang dilakukan dengan cara mencoret, menggores, menorehkan benda tajam ke benda lainnya dan memberi warna sehingga menimbulkan warna (Pamadhi dan Sukadi, 2008). Teknik Inkblot adalah cara membuat kreasi gambar bebas yang dilakukan dengan meneteskan atau menggoreskan cairan pewarna diatas sebagian bidang gambar, setelah itu dilipat menjadi dua kemudian ditekan-tekan setelah itu kertasnya dibuka kembali dan akan terlihat gambar yang kita buat. Jadi perkembangan kreativitas anak bisa dikembangkan diterapkan secara bertahap dari sejak dini. kemampuan kreativitas anak juga dibisa dilatih secara lebih mendalam lagi, yaitu dengan cara memfasilitasi anak dengan sarana dan prasarana yang mendukung agar kemapuan kreativitas anak bisa berkembang sangat baik. 


\section{CONCLUSION}

Berdasarkan hasil penelitian yang dilakukan di TK Handayani Kelompok B mengenai Kreativitas Anak melalui Menggambar dengan Teknik Inkblot, dapat disimpulkan bahwa Kreativitas anak melalui menggambar dengan teknik inkblot di TK Handayani Kebarepan ini sebelumnya masih rendah dan belum berkembang sangat baik. Penerapan teknik inkblot pada kegitaan menggambar untuk mengetahui kreativitas anak di TK Handayani pada Kelompok B. Sebelum kegiatan dimulai guru terkebih dahulu menyiapkan segala macam alat dan bahan (seperti: cat inkblot, tusuk gigi, koran, HVS). Guru terlebih dahulu memberikan arahan tentang bagaimana cara menggunakan teknik inkblot ini. Setelah anak-anak sudah mengerti kemudian guru membaginya menjadi 2 kelompok besar agar memudahkan anak-anak saat menggambar dengan teknik inkblot. hasil penelitian dan pembahasan mengenai Peningkatan Kreativitas Anak melalui Menggambar dengan Teknik Inkblot yang dilakukan di TK Handayani Kebarepan Cirebon pada anak kelompok B yang berjumlah 20 anak, dapat meningkat dengan baik. hal ini terbukti dengan adanya perubahan dalam hal kreativitas anak yang terus meningkat dari setiap siklus nya. Dari hasil penelitian yang dilakukan pada saat Pra Siklus, Siklus 1 dan Siklus 2 mengalami kenaikan yang signifikan yaitu pada saat pra siklus memperoleh hasil sebesar $46 \%$,pada Siklus 1 memperoleh hasil sebesar $64 \%$ ada peningkatan sebesar 18\%, dan pada saat Siklus 2 memperoleh hasil sebesar $88 \%$ ada peningkatan sebesar $24 \%$.

\section{REFERENCES}

Arsad Azhra. (2011). Media Pembelajaran. Jakarta: Raja Grafindo Persada.

Departemen Pendidikan Nasional. 2002.Kamus Besar Bahasa Indonesia. Edisi Ketiga. Jakarta : Balai Pustaka

Choiriyah Widyasari. 2010.Kreativitas dan Keberbakata. Surakarta: PG PAUD FIKIP UMS. Conny R. Semiawan.2009. Kreativitas dan Keberbakatan. Jakarta:PT.Indeks

Fadlillah, Muhammad. (2012). Desain Pembelajaran PAUD. Yogyakarta : AR-RUZZ MEDIA.

Haryanto. 2012. http://belajarpsikologi.com/pengertian-media-pembelajaran/ diakses pada tanggal 1 Desember 2018 pukul $11.00 \mathrm{Wib}$

Huda, Astitin Sanatul. (2018). Peningkatan Kreativitas Menggambar Dengan Permainan Finger PaintingPada Siswa Kelas 1 SDN Purwantoro 2. Malang : Universitas Muhammadiyah Malang 
Aip Saripudin, Ery Khaeriyah, Rosmita Ayu Lestari

Kosasih. A , Angkowo Robertus. 2007. Optimalisasi Media Pembelajaran. Jakarta: PT.Grasindo

Munandar, \& Utami. (2009). Pengembangan Kreativitas Anak Berbakat. Jakarta: Rineke Cipta.

Mujiyanti. (2012). Upaya Meningkatkan Kreativitas Anak Melalui Menggambar Bebas di TK Aisyiyah 2 Giriroto. Universitas Muhammadiyah Surakarta.

Nizar Alam Hamdani \& Dody Hermana. (2008). Classroom Action Research Teknik Penulisan dan Contoh Proposal Penelitian Tindakan Kelas (PTK). Garut: Rahayasa Research and Training

Nuraini. F. 2015. http://journal.student.uny.ac.id/ Jurnal Student UNY

Nursito. 2000. Menggali Kreativitas. Yogyakarta: PT. Mitra Gama Widya.

Pamadhi, Hajar (2009). Seni keterampilan anak. Universitas Terbuka

Pamadhi, Hajar. Sukardi S, Evan \& Muis, Azizah (2010). Seni Keterampolan Anak . Jakaarta: Penerbit Universitas Terbuka

R Aprianti,dkk. 2013. http://repository.unib.ac.id. Jurnal Universitas Bengkulu

Rachmawati, Y., \& Kurniati, E. (2011). Strategi Pengembangan Kreativitas Pada Anak. Jakarta: Kencana Prenada.

Rizkianty.E. 2017. http://repository.radenintan.ac.id/856. Jurnal UIN Raden Intan Lampung

Saripudin, Aip. (2017). Strategi Pengembangan Kecerdasan Naturalis Pada Anak Usia Dini. Awlady Jurnal Pendidikan Anak Usia Dini. Cirebon

Saiful Haq. (2008). Jurus-jurus Menggambar dan Mewarnai dari Nol. Yogyakarta: Mitra Barokah Abadi Press

Sujiono, \& Nuraini, Y. (2009). Konsep Dasar Anak Usia Dini. Jakarta: PT. Indeks.

Sumanto. (2005). Pengembangan Kreativitas Seni Rupa Anak TK. Jakarta: Departemen Pendidikan Nasional

Suryadi, A. (2015). Membuat Media Pembelajaran Untuk Pemula. Surabaya: CV. Garuda Mas Sejahtera.

Susanto, A. (2012). Perkembangan Anak Usia Dini. Jakarta: Kencana Prenada.

Suyadi, \& Maulidya Ulfah. (2015). Konsep Dasar PAUD. Bandung: Remaja Rosdakarya.

Wilyani, A. N. (2016). Konsep Dasar PAUD. Yogyakarta: Gava Media.

Wilyani, A. N., \& Barnawi. (2011). Format Pendidikan Anak Usia Dini. Yogyakarta: ArRuzz Media. 
Abdul Aziz, Akhmad Shodikin, Mohammad Rana

Wina Sanjaya. (2011). Penelitian Tindakan Kelas. Jakarta: Jakarta Prenada Media Group.

Y Herlini, S Suhartono, S Muchtar-2014- http://repository.unib.ac.id/8630/ Jurnal Universitas Bengkulu. 